\title{
Introduction of Chinese Mass Spectrometry Society
}

\author{
Jinying Li \\ President of Chinese Mass Spectrometry Society \\ Received Novermber 17, 2011; Accepted Novermber 17, 2011 \\ First published on the web December 15, 2011; http://dx.doi.org/10.5478/MSL.2011.2.4.077
}

Key words: Chinese mass spectrometry society, mass spectrometry

The establishment and development of mass spectrometry can be dated back to early last century. The famous British physicist J. J. Thomson's invention of hyperbolic unit and his creative work on the instrument opened up a new era of mass spectrometry. In recent years mass spectrometry technology has become an indispensable means of cutting-edge analytical techniques. It not only plays an irreplaceable role in the application of nuclear science, basic science, earth science, cosmology, and other traditional disciplines, but also be widely used in national security, basic medical research, disease prevention, clinical research, protein science, innovative medicines, food and drug safety, emergency response, customs and quarantine, and new emerging disciplines such as new materials and new energy, etc.

Chinese Mass Spectrometry Society was founded in 1980. The eighth council was elected in the election at expiration of office terms at the end of 2008, and researcher Jinying Li Jinying was elected chairman. The tenet of Chinese Mass Spectrometry Society is to unite mass spectrometry academic colleagues, promote the progress of mass spectrometry jointly, and make mass spectrometry technology serve the community better. According to the recent development of mass spectrometry technology, the society for mass spectrometry is divided into the following five sub committees: inorganic mass spectrometry, organic mass spectrometry, biomedical mass spectrometry, isotope mass spectrometry, and mass spectrometry device and education professional committee, etc.

As a branch of the Chinese Physical Society, Chinese Mass Spectrometry Society observe relevant constitutions of Chinese Physical Society, admit members actively and expand team of society, while carefully get down with daily works to ensure the normal operation of the society. Especially, in the joint efforts of the society leadership, members of the council and mass spectrometry colleagues, the following significant achievements have been made in recent years:

First, Chinese Mass Spectrometry Society has carried out extensive domestic and international academic exchanges.

*Reprint requests to Dr. Jinying Li

E-mail: lijinying@vip163.com
Activating academic atmosphere is the prime objective of the society development, and it is also the work greatly concerned by vast number of members. The society and the professional committee have organized academic conferences many times to strengthen domestic and international exchanges and cooperation, and promote China's prosperity and development of mass spectrometry.

The society will hold a conference each year, and the 31 st Annual Academic Conference was held at Weiyang Lake Hotel in Xi'an from August 6 to August 10 this year. The theme of this conference is: new methods, new techniques, and new applications of cutting-edge mass spectrometry. More than 1,000 scholars appeared in the meeting, and the conference met with complete success. Last year, the annual academic conference and the 3rd World Chinese Mass Spectrometry Seminar was successfully held from July 30 to August 1 in Changchun City, Jilin Province. The first session of mass spectrometry academic seminar was held successfully by Xinjiang University in 2006, and the second session was successfully held in Taiwan in 2008. A decision was made in this conference that the fourth World Chinese Mass Spectrometry Conference will continue to be held in Taiwan in 2012, which is under preparation currently.

Chinese Mass Spectrometry Society also sent delegations to actively join the annual conferences in mass spectrometry held in asia-pacific region, and actively organized each session of the conferences as a co-support unit.

Meanwhile, Chinese Mass Spectrometry Society was actively involved in and co-organized Beijing Conference and Exhibition on Instrumental Analysis (BCEIA). BCEIA, which is coorganized by Mass Spectrometry Society, Optical spectrum Society, Electrochemical Society, Spectroscopy Society, Chromatography Society, and other societies, is the grand meeting of international professional academic exchange and analytical instruments exhibition. BCEIA holds once every two year, and enjoys a fairly high reputation both at home and abroad.

The Mass Spectrometry Society irregularly organizes the domestic salon activities on mass spectrometry, which are the most active in the past two years. Until Nov. 2011, 50 sessions of mass spectrometry salon had been held successively 
in Tsinghua University, Peking University, Beijing Normal University, the Second Artillery General Hospital and 307 Hospital of the People's Liberation Army and other relative units. About 200 individuals participated in each session, who are respectively from Tsinghua University, Peking University, The Second Artillery Force General Hospital, Military Medical Science Academy of the PLA, Fermentation Research Institute, 307 Hospital of the People's Liberation Army, National Institute of Biological Sciences (Beijing), Institute of Botany, the Chinese Academy of Sciences, AB corporation, and so on. The delegates communicated extensively for relatively difficuly issues in the meeting, which will be greatly helpful for the actual work in the future.

The Mass Spectrometry Society will strengthen academic exchanges at home and abroad as always, actively organize the national academic exchange conference for members, participate in the international academic exchange activities, promote the international exchanges and cooperation, and organize the International Mass Spectrometry Conference.

First of all, Mass spectrometry society will keep close ties with the International Mass Spectrometry Society, the American Society for Mass Spectrometry, the European Society for Mass Spectrometry, the British Mass Spectrometry Society, the Belgian Society for Mass Spectrometry, the Dutch Society for Mass Spectrometry, the Mass Spectrometry Society of Japan, the Korean Society for Mass Spectrometry, the Indian Society for Mass Spectrometry, and other international Mass Spectrometry societies. By organizing various academic activities, inviting international renowned experts and chinese scientists on mass spectrometry to participate in various academic conferences, the mass spectrometry society will promote academic exchanges and provide cooperative opportunities between domestic and foreign mass spectrometry scholars, and thus provide a platform for domestic workers to know about international frontier technologies and the latest developments of mass spectrometry.

In the next place, Chinese Mass Spectrometry Society encourages and organizes the directors, editors and members of the society to actively participate in international mass spectrometry academic conferences, promotes international exchange and cooperation, positively organizes the academic exchange activities between three districts of Cross-straits. Especially, the society strengthens communication and cooperation with the Chinese-American Society for Mass Spectrometry, the Taiwan Society for Mass Spectrometry, the Hong Kong Society of Mass Spectrometry, and other Chinese mass spectrometry organizations, while actively sends delegations to go abroad for exchange activities on mass spectrometry.

Once again, Chinese Mass Spectrometry Society actively strengthens cooperation with other domestic academic groups including related instrumental analysis websites and instruments corporations, and holds academic exchanges many times which includes mass spectrometry training courses cooperatively with the Analysis and Test Encyclopedia Website, the Instrument
Information Network, and the China Chromatography Network. The society positively organized a variety of multi-class mass spectrometry science courses correlating with the release of new instruments of relevant instrument corporations, which makes the academic activities organized by the society become the most leading edge lectures in mass spectrometry and the learning paradise for the youth.

In the end, as the members of editorial board of Green and Sustainable Chemistry (GSC), Mass spectrometry letters, Natural Science, RCM, and JMS, the directors and editors of the Chinese Mass Spectrometry Society positively reinforce communication and academic exchange with these international principal mass spectrometry periodicals.

Second, the construction and development of the Chinese Mass Spectrometry Society is becoming more perfect, website construction is enhanced, and information management of the Society is promoted.

Under the leadership of the Chinese Mass Spectrometry Society's leaders, the organization, construction and development of the society are strengthened, and information management of the Society is promoted. In 2001, the office of the Chinese Mass Spectrometry Society established website for the society which addressed www.cmss.org.cn. Since 2009, timely updating of the up-to-date information and the latest developments of mass spectrometry through the websites promotes the society's exchange.

From now on, by cooperating and communicating with other domestic websites, and making full use of the function of the Chinese Mass Spectrometry Society's official website, Chinese mass spectrometry will unite national mass spectrometry academic colleagues $£$ jointly promote the progress of mass spectrometry, and thus make mass spectrometry technology serve the community better.

Third, the Chinese Mass Spectrometry Society will continuously improve academic standards, and make Journal of Mass Spectrometry a success.

Mass Spectrometry Journal, the proceeding of Chinese Mass Spectrometry Society, was initiated in 1980, and was changed to be published bimonthly (published in the odd month) in 2008. The Journal is an academic periodical sponsored by Beijing KYKY Instrument Technology Development LTD. and the Chinese Mass Spectrometry Society, and is undertaken by the China Institute of Atomic Energy. This journal mainly publishes the new theory, methods, technology, and the application of mass spectrometry in physics, chemistry, biochemistry, materials chemistry, nuclear chemistry, geochemistry, life sciences, and other basic subjects.

With the assistance of directors, members of editorial board, experts in various fields, and extensive authors and readers, mass spectrometry journal, which is the proceeding of Chinese mass spectrometry society, has made some achievements in recent two years. Period for dissertation published has been shortened from 14 months to 7 months, and the volume of received dissertations has been increased tremendously. The quality of dissertations published by 
mass spectrometry journal has been improved, and the journal impact factor also makes a substantial improvement, which has raised from 0.198 in 2003 to 0.542 in 2008 . The mass spectrometry journal ranked 29 in total 31 kinds of journals in physics classification in 2003, whereas it ranked 17 in total 34 kinds of journals in 2008.

As the proceeding for Chinese mass spectrometry, mass spectrometry journal has been included respectively by American Chemical Abstract (CD edition, CODEN ZXHUBO), British Analysis Abstract, Russia Abstract Journal, China Science Citation Database, China Science and Technology Dissertation Database, China Biology Abstract, China Biology Literature Database, China Academic Journal Comprehensive Evaluation Database(CAJCED), China Journal Full Text Database (CJFD), China Academic Journal(CD edition), Chinese Science and Technology Journal Database, China Inorganic Analysis of Chemical Abstracts, and Founder Apabi electronic journals, etc. Furthermore, mass spectrometry journal has also been included by Chinese and foreign network databases such as Wanfang data and digital periodicals, Chongqing VIP Database of scientific journals, Taiwan Chinese Electronic Periodical Services-- SoftBrands Network (CEPS), Scholar Digital Journal, etc.

Mass spectrometry journal has maintained its own website www.jcmss.com.cn in recent years. MagTech's online editing system has been adopted, thus online submission of dissertation by author, online screening by experts, and remote editing by responsible editor have been achieved by the integrative platform, which has greatly improved the work efficiency. In addition, it is very convenient for the author to make online manuscript inquiry, track manuscript auditing process, and contact with responsible editor at any time.

The development of mass spectrometry science and the growth of Mass Spectrometry Society in the past two years provide rare opportunities for the future development of mass spectrometry journal. Chinese Mass Spectrometry
Society will make efforts to overcome various difficulties to make mass spectrometry journal, the proceeding of Chinese mass spectrometry, better and stronger; to make the journal an important platform for academic communication of domestic mass spectrometry researchers, and make contributions to the development of mass spectrometry scientific research.

In order to attract national researchers on mass spectrometry to provide higher level of research papers, make more colleagues in mass spectrometry community and researchers interested in the study of mass spectrometry pay attention to the papers published by the Journal, make Mass Spectrometry Journal actually become the common homestead and field for all of the national research workers in mass spectrometry, become the stage displaying China's level of mass spectrometry studies, and further become the window for the international academic community to know about our mass spectrometry studies, several aspects for the Mass Spectrometry Journal to be reinforced in the future is listed:

The Journal should actively provide good quality services for the journal's authors and readers, borrow ideas from the international and other domestic journals, make full use of the facilitates provided by the network technologies, shorten paper auditing period, and timely provide Information Services of Periodicals Catalogues.

The publications should orient to the vast number of the national colleagues in mass spectrometry, not limited to the national research units. Meanwhile, it should actively draw on the innovative work by the non-military colleges and universities, and invite engineers and technicians engaging in the development, repair, maintenance, and upgrading of the mass spectrometry instrument and equipment to share what they have learned in the application and development of mass spectrometry technology. A special column should also be set up for the mass spectrometry manufacturers to introduce their new instruments, products and technologies, etc. 